\title{
3 Genetic basis of control of Rhynchosporium secalis infection 4 and symptom expression in barley
}

\author{
5 M. E. Looseley - A. C. Newton - S. D. Atkins • \\ 6 B. D. L. Fitt - B. A. Fraaije - W. T. B. Thomas • \\ 7 R. Keith $\cdot$ M. Macaulay $\cdot$ J. Lynott $\cdot$ D. Harrap
}

Received: 18 February 2011/Accepted: 5 July 2011

(C) Springer Science+Business Media B.V. 2011

\begin{abstract}
The genetic basis of several different components of resistance to Rhynchosporium secalis in barley was investigated in a mapping population derived from a cross between winter and spring barley types. Both the severity of visual disease symptoms and amount of $R$. secalis DNA in leaf tissues were assessed in field trials in Scotland in the $2007 / 2008$ and 2008/2009 growing seasons. Relative expression of symptoms was defined as the residual values from a linear regression of amount of $R$. secalis DNA against visual plot disease score at GS 50. Amount of $R$. secalis DNA and visual disease score were highly correlated traits and identified nearly identical QTL. The genetic control of relative expression of symptoms was less clear. However, a
\end{abstract}

M. E. Looseley $(\varangle) \cdot$ A. C. Newton

W. T. B. Thomas - R. Keith - M. Macaulay - J. Lynott The James Hutton Institute, Invergowrie, Dundee DD2 5DA, UK

e-mail: mark.looseley@scri.ac.uk

S. D. Atkins - B. D. L. Fitt - B. A. Fraaije

Rothamsted Research, Harpenden, Hertfordshire AL5

2JQ, UK

D. Harrap

KWS UK Ltd, 56 Church Street, Thriplow, Nr. Royston, Hertfordshire SG8 7RE, UK

Present Address:

B. D. L. Fitt

University of Hertfordshire, Hatfield, Hertfordshire AL10 $9 \mathrm{AB}, \mathrm{UK}$
QTL on chromosome $7 \mathrm{H}$ was identified as having a significant effect on the expression of visual disease symptoms relative to overall amount of $R$. secalis colonisation.

Keywords Asymptomatic colonisation - Disease resistance $\cdot$ Leaf scald $\cdot$ Mapping population $\cdot$ QTL

\section{Introduction}

Rhynchosporum secalis (Oudem) J.J. Davis, the pathogen that causes 'rhynchosporium', 'barley leaf blotch' or 'scald', in Hordeum vulgare L. (barley). is one of the most economically important barley pathogens worldwide, particularly in cool humid environments, causing reductions in both yield and grain quality (Zhan et al. 2008). Average yield losses (from Canada) have been estimated at 5-10\% (Turkington et al. 1998), though losses of up to $40 \%$ have been reported under conditions favourable for the disease (Xi et al. 2000). Mapping studies have located a number of major resistance $(R)$ genes and quantitative trait loci (QTL) affecting expression of resistance to $R$. secalis; these are predominantly located on barley chromosomes $2 \mathrm{H}, 3 \mathrm{H}$ and $7 \mathrm{H}$ (Zhan et al. 2008). Whilst current control strategies in the UK frequently include a fungicide treatment, commercial cultivars with good levels of resistance, probably due

\begin{tabular}{|l|lll|}
\hline Journal : Medium 10681 & Dispatch : 11-7-2011 & Pages : 10 \\
Article No. : 485 & $\square$ LE & $\square$ TYPESET \\
MS Code : EUPH4908 & $\checkmark$ CP & $\checkmark$ DISK \\
\hline
\end{tabular}


to major gene factors on chromosomes $3 \mathrm{H}$ and $7 \mathrm{H}$, are available. However, breakdown of such sources of host resistance is generally rapid, if they are used in widespread commercial deployment of resistant cultivars, as $R$. secalis populations are able to evolve rapidly (Abang et al. 2006; Newton et al. 2001). Therefore, novel sources of resistance to $R$. secalis represent a valuable resource for plant breeders. In particular, the identification of quantitative resistance loci, which have previously been shown to be more durable than major resistance loci in other hostpathogen systems (Brun et al. 2010), is of considerable importance. To ensure food security, particularly for subsistence farmers who cannot afford to use fungicides, it is essential to breed for resistance that is not rapidly rendered ineffective by changes in pathogen populations.

In the UK, ratings for 'field resistance' to $R$. secalis, based on visual assessment of disease symptoms on leaves of barley crops/field plots, are generally and consistently greater in winter (autumn sown) barley than in spring barley (http://www.hgca.com). This difference is greatest when spring types are autumnsown and scored for disease symptoms alongside winter types (Newton et al. 2004) but it is maintained even when each type is grown in the appropriate season. Whilst the origin of this difference remains a subject for speculation, such observations suggest that winter barley germplasm represents a potential source of resistance genes that could be incorporated into spring lines. Thus, populations derived from crosses between spring and winter parents are of considerable interest to the study of the genetic basis of resistance to R. secalis.

A problem associated with the use of populations segregating for major developmental genes to address such questions is the extent to which field resistance QTLs are simply pleiotropic expressions of broader morphological differences. For example, in a cross between the spring barley genotypes B83-12/21/5 and Derkado, two known semi-dwarfing genes ( $s d w 1$ and ari-eGP) were consistently associated with QTL for resistance to $R$. secalis (Thomas et al. 2010), with semi-dwarf types showing more disease symptoms. Given that secondary infection is mediated by splash dispersal of $R$. secalis spores (Fitt et al. 1988), this finding almost certainly reflects a pleiotropic effect of height rather than an interaction between host and pathogen and therefore needs to be accounted for in selection for resistance.

$R$. secalis is known to have a long asymptomatic phase in crop leaves between infection and development of visual symptoms (Davis and Fitt 1990; Walters et al. 2008) and recent work has shown that the pathogen may complete its life cycle and produce asexual spores on apparently healthy leaf tissue (Atkins et al. 2010; Fountaine et al. 2010). Understanding the mechanisms that cause the switch between asymptomatic and symptomatic $R$. secalis colonisation and its genetic basis could be important for devising breeding strategies for producing cultivars with durable resistance. It is therefore necessary to determine whether suppression of disease symptoms (or more generally, the level of disease symptom expression relative to the amount of pathogen colonisation) represents a separate mechanism of resistance from that which prevents the infection that precedes colonisation (Hahn et al. 1993; Lehnackers and Knogge 1990). Viewed from an evolutionary perspective, such a mechanism would imply that the expression of disease symptoms represented a yield cost to the plant greater than that caused by pathogen colonisation alone. Resistance that differentially restricts colonisation and symptom development will also affect disease risk in relation to other epidemiological factors (e.g. through differential effects on amounts of inoculum within a field and thus, potentially, a differential response to environmental factors that may cause a switch between asymptomatic and symptomatic colonisation). Therefore a better understanding of the genetic basis of resistance in UK barley crops will also facilitate more appropriate targeting of fungicides.

Severity of disease symptoms and amount of pathogen colonisation can be measured using visual assessment and quantitative real-time PCR (qPCR), respectively, as described by Fountaine et al. (2007). The current study utilised these two approaches to investigate the genetic basis of resistance to rhynchosporium in a mapping population from a cross between winter and spring barley types. An additional aim was to define relative disease expression based on these measurements, and use this to investigate whether the suppression of rhynchosporium symptom expression (following successful infection by $R$. secalis) has a distinct genetic basis in barley.

\begin{tabular}{|c|c|c|}
\hline Journal : Medium 10681 & Dispatch: 11-7-2011 & Pages: 10 \\
\hline Article No. : $\mathbf{4 8 5}$ & $\square \quad \mathrm{LE}$ & $\square \quad$ TYPESET \\
\hline MS Code : EUPH4908 & $\boldsymbol{V}_{\mathrm{CP}}$ & $\boldsymbol{~ D I S K}$ \\
\hline
\end{tabular}




\section{Materials and methods}

Plant material, mapping population and markers

A doubled-haploid mapping population was produced by microspore culture from the $F_{1}$ progeny of a cross between the spring barley cultivar Cocktail and the winter barley inbred line WB05-13, derived from a cross between the winter cultivars Leonie and Pearl. $\mathrm{Cv}$ Leonie was bred by Nordsaat in Germany and was the most resistant cultivar on the UK recommended list during its period of special recommendation from 2001 to 2003. As it also had resistance to barley yellow mosaic virus strains BaMVV and BaYMV-1 and good malting quality, it had a special recommendation for the UK (http://www.hgca.com/varieties/2003/common/20 0212/recommendedlists/data/WBcolour.pdf). Cv Pearl was bred by Limagrain (formerly Nickersons Seeds) and has been recommended for growth in the UK since 1999; it has been the main winter barley malting cultivar grown by farmers over this period. It was initially rated as having a good resistance to $R$. secalis, being rated ' 8 ', on a 1-9 scale of increasing host resistance as described in the recommended list protocols (www. hgca.com). Leonie originally had the best rating of ' 9 ,' but its resistance rating had declined to '5.9' by 2010 (www.hgca.com). Cv Cocktail was first recommended for cultivation in the UK in 2003 and was formerly an accepted spring barley malting cultivar in the UK. It does not possess either of the two $R$ genes for resistance to $R$. secalis found in current UK spring barley cultivars and had a moderate resistance rating of ' 5 ' when first recommended, which had increased slightly to ' 5.9 ' in the 2010 recommended list (www.hgca.com).

WB05-13 was bred to combine the resistance to R.secalis and BaYMV-1 of Leonie with the accepted malting quality attributes of Pearl; thus progeny from its cross with Cocktail are expected to segregate for resistance to $R$. secalis and to BaYMV-1 as well as for the $s d w 1$ dwarfing gene found in Cocktail. In addition, WB05-13 has the Vrsl.t allele at the VRS1 locus on chromosome $2 \mathrm{H}$ and the mapping population therefore also segregates for the deficiens ear type. Over 800 individual plants were derived from microspore culture of the $\mathrm{F}_{1}$ progeny; 550 lines were fertile and produced sufficient seed for a field multiplication plot that was sown at the James Hutton
Institute in autumn 2006. Immediately prior to harvest, a single plant was recovered from each of the multiplication plots. For the first 191 lines, the seed from this single plant was used as the primary seed source for agronomic trials and a reference seed stock. The remainder of the plot was harvested with a small plot combine and the seed was used as secondary seed source for agronomic trials.

A single seed was taken from the reference stock of each line and grown in the glasshouse. A $2-3 \mathrm{~cm}$ length of leaf tissue was harvested from the youngest leaf of each of these barley plants at the 3-4 leaf stage. Leaf material was harvested into 96 deep well blocks (VWR \# AB-0932) containing a stainless steel ball bearing (Spex Centriprep Ltd \#662316). Total plant DNA was extracted using the Tepnel Nucleoplex Automated DNA Isolation, according to the manufacturer's instructions using the Standard Plant Lysis and Plant Purification protocols (Tepnel \#: 33300). DNA concentration was estimated using Quant-iT Picogreen dsDNA Assay kit (Invitrogen \#P11496). Sufficient volume of a 1:200 working dilution of picogreen reagent in $1 \times$ TE was made up and $197 \mu \mathrm{l}$ was pipetted into white flat bottomed assay plates (Thermo Fisher \#DIS-940-010T). $3 \mu \mathrm{l}$ of DNA samples to be measured and DNA standards that were made up at $75,50,25,12.5,6.25,3.13,1.56$ and $0 \mathrm{ng} / \mu \mathrm{l}$ from Lambda DNA (Invitrogen \#1363336) were added to the picogreen reagent. Plates were incubated for 2 min then absorbance readings were taken from a Flouroskan Ascent plate reader. A standard curve was created using the DNA standards ( $R^{2}$ value between 0.950 and 0.999$)$ and was then applied to the unknown samples to estimate concentrations. DNA concentrations were normalized to $50 \mathrm{ng} / \mu \mathrm{l}$ in preparation for genotyping.

A $5 \mu \mathrm{l}$ aliquot of DNA from each line was used for genotyping with a custom Bead Xpress Oligo Pool Assay (Illumina), which comprised 384 single nucleotide polymorphism (SNP) markers that had been selected (based on their quality, informativeness and coverage of the barley genome) from the set of 1536 gene-based SNP markers previously developed for the first Illumina production Barley Oligo Pooled Array (Close et al. 2009). Allele calls were made as SNP bases using the Illumina Beadstudio software and validated manually.

\begin{tabular}{|l|lll|}
\hline Journal : Medium 10681 & Dispatch : 11-7-2011 & Pages : 10 \\
Article No. : 485 & $\square$ LE & $\square$ TYPESET \\
MS Code : EUPH4908 & $\checkmark$ CP & $\checkmark$ DISK \\
\hline
\end{tabular}


The individual base calls for each marker were converted into 'a' (Cocktail), 'b' (WB05-13) and'(missing) scores by comparison to the parental scores for input into JoinMap 4 (Van Ooijen 2006). Before conversion, monomorphic markers or markers that had a large number $(>15 \%)$ of heterozygous calls were discarded, since the former are uninformative in mapping and the latter reflect poorer quality markers. There was a small proportion of remaining heterozygotes in the data and individual lines were removed where there were more than $15 \%$ of these since the DNA quality and/or quantity was suspect. The few remaining heterozygous calls were re-classified as missing. Markers that consistently remained linked to each other between LOD 2.0 and LOD 10.0 were classified into groups that were each assigned to an individual barley chromosome by comparison with previously mapped positions for each marker (Close et al. 2009). Marker order and position within each linkage group was estimated by using the regression mapping option of Joinmap 4.0 with Kosambi's mapping function. In all cases, linkage phase was identical to that predicted by the parental genotypes.

Field trials

Seed from the primary and secondary seed sources was used to sow the 190 lines of the mapping population in field trials over two winter barley growing seasons (2007/2008 and 2008/2009) at the James Hutton Institute rhynchosporium disease nursery (Table 1). Cocktail, Leonie and Pearl together with seven other controls were included in the trial to give a trial with 200 entries. Field trials were arranged in a row and column design with two replicates and plot sizes of $2 \mathrm{~m} \times 1.5 \mathrm{~m}$ at a seed density estimated to produce 250 established plants $\mathrm{m}^{-2}$. The plots were combine drilled with fertiliser applied at a rate of $30.5 \mathrm{P}$ and $87 \mathrm{~K} \mathrm{~kg} \mathrm{ha}^{-1}$ and received an $N$ application of $51 \mathrm{~N} \mathrm{~kg} \mathrm{ha}^{-1}$ at average growth stage (GS) 30 (Zadoks et al. 1974) and $69 \mathrm{~N} \mathrm{~kg} \mathrm{ha}^{-1}$ at GS 40. Weeds were controlled by applying a herbicide but no fungicides were applied. Primary inoculum was from residual barley crop debris from the previous harvest and overhead irrigation was applied on alternate days to encourage secondary disease spread, commencing when soil
Table 1 Times of operations during field trials on development of rhynchosporium on two replicate plots of each of 191 lines of a spring $\times$ winter barley mapping population grown in the James Hutton Institute disease nursery in the 2007/2008 and 2008/2009 growing season. Where known, the growth stage corresponding to the date is given in parentheses

\begin{tabular}{lcc}
\hline Operation & $2007 / 2008$ & $2008 / 2009$ \\
\hline Sowing & 26 Oct 2007 & 28 Oct 2008 \\
$\begin{array}{l}\text { Plot disease } \\
\text { assessments }^{\mathrm{a}}\end{array}$ & 19 May 2008 & 22 April 2009 \\
& 04 June 2008 & 01 May 2009 \\
& (GS 50) & (GS 31-50) \\
& 17 June 2008 & 14 May 2009 \\
& 30 June 2008 & 19 May 2009 \\
& 11 July 2008 & 09 June 2009 \\
& & (GS 35-60) \\
& & 23 June 2009 \\
Samples for qPCR & & 01 April 2009 \\
& 05 May 2008 & (GS 26-30) \\
& (GS 26-30) & 28 May 2009 2008 \\
(GS 50) & (GS50) \\
\hline
\end{tabular}

${ }^{a}$ Assessment of area of visual disease symptoms across entire plots measured on a 1-9 scale (Newton and Hackett 1994)

b Date at which leaf samples from selected plants were taken for qPCR estimation of amount of $R$. secalis DNA

moisture levels decreased sufficiently to avoid water logging (late April or early May). Assessments of rhynchosporium disease symptoms (visible lesions) for whole plots were made at several growth stages (Table 1) using a 1-9 scale (Newton and Hackett 1994), where 1 represented no visible symptoms in the entire plot and 9 indicated complete leaf death due to rhynchosporium. In addition, the upper three leaves from five randomly selected plants from each plot were taken for qPCR quantification of $R$. secalis DNA at GS 50 in 2008 and at GS 26 (where five whole plants were sampled) and 50 in 2009. For each of the three leaves (and for whole plants) samples from within a plot were combined for subsequent qPCR analysis. Total DNA was extracted from the samples using a high salt extraction protocol according to Bearchell et al. (2005). R. secalis DNA was quantified from $50 \mathrm{ng}$ of the sample of total DNA using a qPCR protocol described by Fountaine et al. (2007). Plot disease scores were normalized using a natural logarithm transformation prior to further analysis in order to normalize the data.

Relative disease expression scores (i.e. the differences between areas of visual symptoms that would be

\begin{tabular}{|l|lll|}
\hline Journal : Medium 10681 & Dispatch : 11-7-2011 & Pages : 10 \\
Article No. : 485 & $\square$ LE & $\square$ TYPESET \\
& MS Code : EUPH4908 & $\checkmark \mathrm{CP}$ & $\checkmark$ DISK \\
\hline
\end{tabular}


expected, given the amounts of pathogen colonisation, and the observed areas of visual symptoms) were obtained by fitting a standardised major axis linear regression model to the relationship between the amount of $R$. secalis DNA (GS50) and visual plot disease score (GS50) using the lmod2 package in R (http://www. $\mathrm{R}$-project.org). Residuals (defined as orthogonal distances from the fitted line) were calculated and taken as a measure of relative disease expression. This method was used rather than taking the residuals from a least squares linear regression to account for the presence of significant measurement error in both variables.

\section{Statistical analysis}

Statistical analyses were made using GenStat software (Payne et al. 2009). Trait means for each of the DH lines for each season were estimated using a REML mixed model, fitting barley DH line as a fixed effect, and a random model comprising replicate. The analysis was repeated using random models with additional terms to account for spatial effects (selected from: random row, random column, correlated row, correlated column). The simplest model for which there was no significantly better, more complex, model was used to estimate line means. Phenotypic variance $\left(V_{\mathrm{p}}\right)$ and additive genetic variance $\left(V_{\mathrm{a}}\right)$ for each trait were estimated by REML, fitting the effect of environment (season), replicate (within environment) and DH line as the random model. Additive genetic variance was estimated as half of the between $\mathrm{DH}$ lines variance component (equivalent to $2 V_{\mathrm{a}}$ ). Heritability estimates were calculated as the ratio between $V_{\mathrm{a}}$ and $V_{\mathrm{p}}$. For each pair of traits, additive genetic covariances $\left(\operatorname{cov}_{\mathrm{a}}\right)$ were estimated by a REML analysis of the sum of the two traits. $\operatorname{cov}_{\mathrm{a}}$ was calculated as half of the additive genetic variance of the sum of the two traits minus $V_{\mathrm{a}}$ for each of the two traits.

\section{QTL analysis}

Composite interval mapping was done by using the Biometris QTL mapping procedure library (Boer et al. 2007) found in GenStat 12 (Payne et al. 2009). This methodology enables the correct variance/ covariance model to be used to account for the relationships between genotype and environment in 'multi-environment' trials. The two growing seasons were treated as separate environments and the
VGESELECT procedure was used to identify the most appropriate model. The marker genotypes and their map positions were used to estimate genetic predictors at $2 \mathrm{cM}$ intervals using the QIBDPROBABILITIES procedure. These predictors were then included in a simple interval mapping genome scan using the procedure QMQTLSCAN with a minimum distance of $30 \mathrm{cM}$ between QTL maxima. The threshold value $\left(-\log _{10} P\right)$ for identifying a QTL was 3.36, estimated to be the genome wide error rate at $P<0.05$ by the method of $\mathrm{Li}$ and $\mathrm{Ji}$ (2005). The predictors associated with the maximum value for each QTL were then included as cofactors in a composite interval mapping scan using QMQTLSCAN and the procedure was repeated iteratively until there was no change in the selected co-factors. The final list of cofactors was used in the procedure QMBACKSELECT to iteratively eliminate any nonsignificant loci. Finally, the effects and type of action (QTL main effect or QTL $\times$ environment interaction) of those remaining were estimated using the QCANDIDATES procedure.

\section{Results}

Genotyping and genetic map construction

Of the original 190 lines, six were discarded because they had a high proportion of missing or heterozygous allele calls. Additionally, 161 markers were discarded because they were monomorphic or highly skewed and a further 48 were discarded during the construction of the genetic map due to a high proportion of predicted genotyping errors. Therefore, the final genetic map was based on 184 lines and 175 markers. Marker chromosome allocation and order were highly consistent with the barley consensus map (Close et al. 2009) but the map size was larger for all chromosomes.

Traits

The severity of the rhynchosporium epidemic (based on visual disease score) was substantially greater in 2008/2009 than in 2007/2008, particularly during later growth stages (Fig. 1). Disease scores for QTL analysis (symptoms and $R$. secalis DNA) were made at approximately GS50. Estimated line means (DH lines only) for log-transformed disease symptom
393 


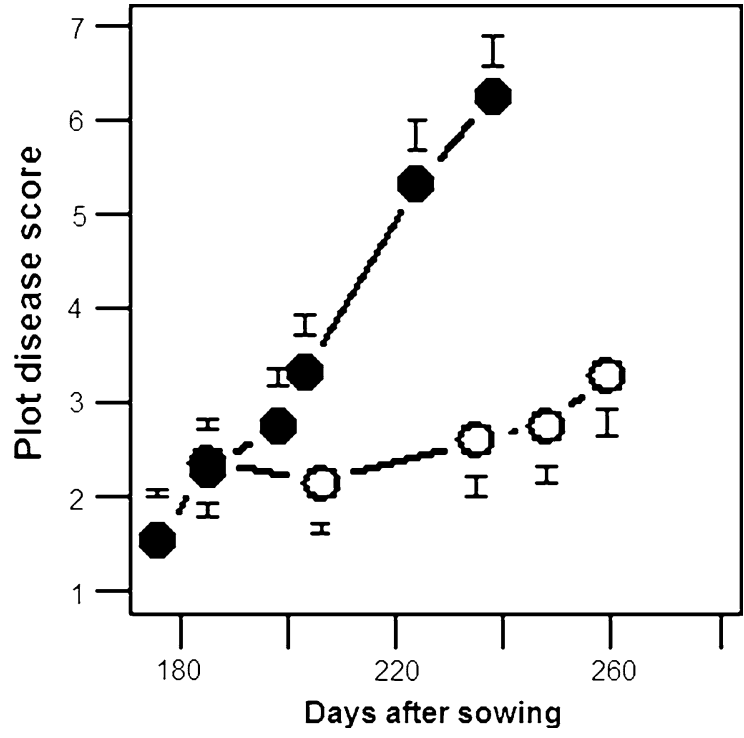

Fig. 1 Progress of rhynchosporium epidemics assessed visually as a proportion of plot area affected by leaf lesions on a 1 (symptomless) to 9 (100\% leaf area covered by lesions) scale (Newton and Hackett 1994) with time (days after sowing in plots) in the James Hutton Institute disease nursery in the 2007/2008 (open symbols) and 2008/2009 (filled symbols) growing seasons. Data presented are the estimated mean plot score across all $191 \mathrm{DH}$ lines in the spring $\times$ winter barley mapping population. Standard errors for each time point are indicated by vertical bars (located below the points for $2007 / 2008$ and above the points for $2008 / 2009$

scores had a mean of $0.81(\mathrm{SD}=0.51)$ in $2007 / 2008$ 401 and 1.08 (SD $=0.50)$ in 2008/2009. Amount of $R$. secalis DNA had a mean of $435 \mathrm{ng}(\mathrm{SD}=2042 \mathrm{ng})$ in $2007 / 2008$ and $12486 \mathrm{ng}(\mathrm{SD}=10731 \mathrm{ng})$ in 2008/2009. Relative disease expression was defined from a regression on standardised primary traits and as such (by definition) had a mean of 0 and standard deviation of 0.56 in both years. In the parental lines, estimated line means for the two winter barley parents had smaller disease scores than those of the spring barley parent in 2007/2008 (Leonie $=0.2$, Pearl $=0.2$, Cocktail $=1.15$ ) but in $2008 / 2009$ only one winter barley parent had a smaller disease score than the spring barley parent (Leonie $=-0.02$, Pearl $=0.4$, Cocktail $=1.6$ ) Fig. 2.

\section{Correlations and heritabilities}

There was a good genetic correlation between plot visual disease score at GS50 and amount of $R$. secalis DNA in leaves (at GS50) $\left(r_{A}=0.91\right)$. The heritability of plot disease score at GS50 (0.59) was substantially greater than that of amount of $R$. secalis DNA (0.08). Relative expression of disease symptoms also had a small heritability (0.03). Phenotypic correlations (2008/2009 only) between early growth stage (GS26) amount of $R$. secalis DNA and later (GS50) plot disease score were small $\left(r_{p}=0.18\right)$ compared to the phenotypic correlation between early and later growth stage plot disease score $\left(r_{p}=0.67\right)$.

QTL genome scans

The final QTL model based on visual plot disease scores identified three significant QTL effects (Table 2). These QTL effects were on chromosomes $2 \mathrm{H}, 3 \mathrm{H}$ and $7 \mathrm{H}$. The position of the QTL on $3 \mathrm{H}$ is identical to that of a height QTL (data not shown) at the known position of the semi-dwarfing gene $s d w 1$ (between markers 11_10515 and 11_20612). Given what is known about the epidemiology of rhynchosporium and that crop height has previously been reported as a mechanism of disease escape, this QTL very probably represents a pleiotropic effect of $s d w 1$. Whilst the QTL effect on 7H (located between markers 11_11098 and 11_10169) is in a similar position to Vrn-H3 (a determinant of flowering time located on the short arm of chromosome 7H), Vrn-H3 is more distal than the $7 \mathrm{H}$ resistance QTL and it is inferred that it is flanked by markers 11_20162 and 11_11014 (44-84 cM) on the current map. Similarly, whilst an $R$ gene for resistance to $R$. secalis (Rrs2) has been mapped to the short arm of chromosome $7 \mathrm{H}$ (Hanemann et al. 2009), its mapped position is distal to the QTL effect identified here, being between markers 11_11179 and 11_20245 (0-7 cM on this Map) (unpublished data). Similarly, for the resistance QTL on 2H (located between markers 11_10791 and 11_10085), a QTL affecting flowering time (Flt-2L) has been reported on the long arm of chromosome $2 \mathrm{H}$ (Chen et al. 2009). However, this locus does not appear to be segregating in this population, with no significant QTL effects for ear emergence or height detectable (data not shown). In addition, the position of Flt-2 is likely to be proximal to that of this resistance QTL, with the rice region that is collinear to the region containing Flt-2 (Chen et al. 2009) being located between markers 11_21459 and 11_10383 on this map. Likewise, the final QTL model for amount of $R$. secalis DNA identified three resistance QTL
428

429

430

431

432

433

434

435

436

437

438

439

440

441

442

443

444

445

446

447

448

449

450

451

452

453

454

455

456

457

458

459

460

461

462

463

464

465

\begin{tabular}{|l|lll|}
\hline & Journal : Medium 10681 & Dispatch : 11-7-2011 & Pages : 10 \\
Article No. : 485 & $\square$ LE & $\square$ TYPESET \\
& MS Code : EUPH4908 & $\checkmark \mathrm{CP}$ & $\checkmark$ DISK \\
\hline
\end{tabular}



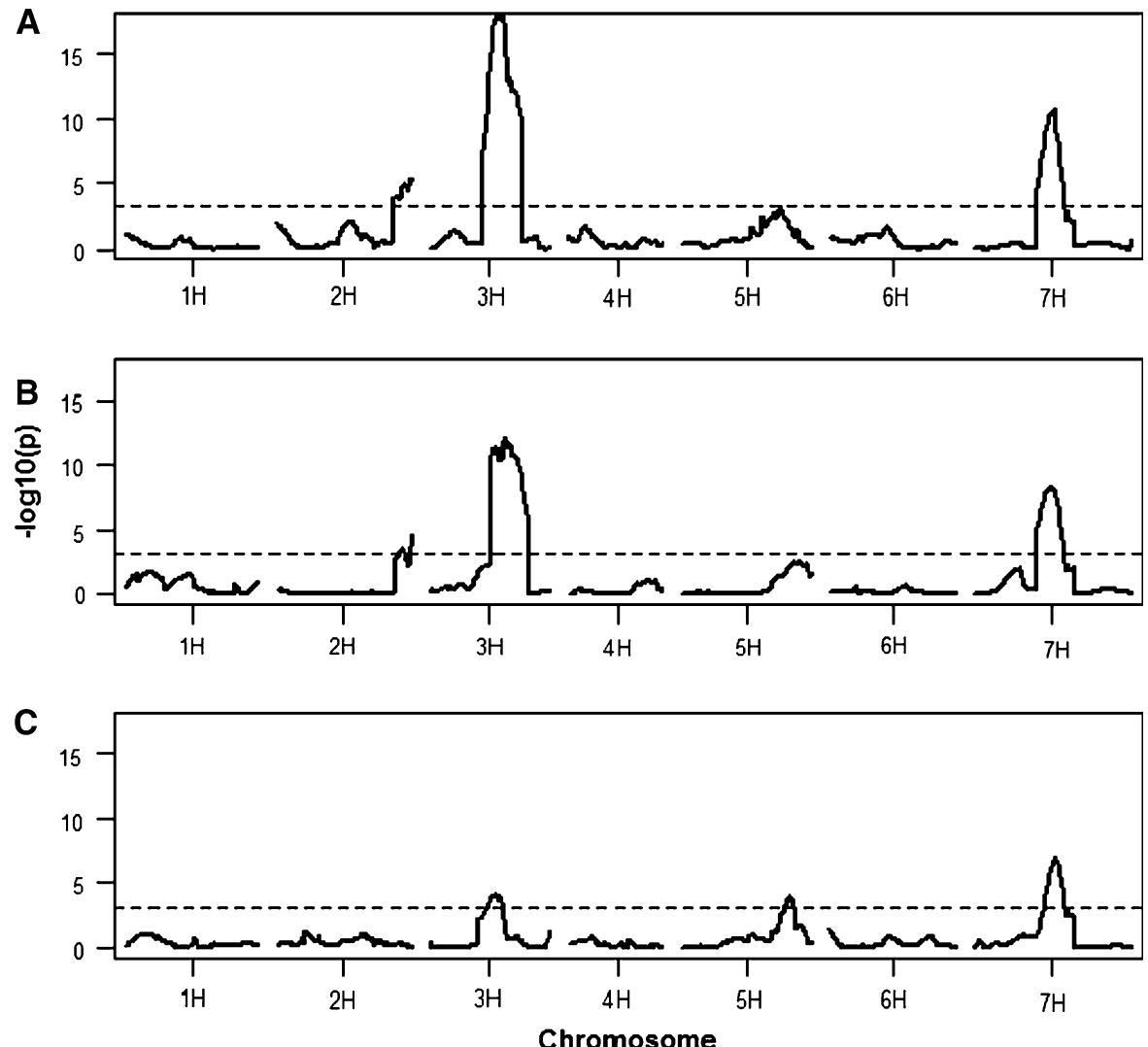

Fig. 2 Results from a multi-environment QTL genome scan for three different assessments of disease severity used to identify barley resistance to $R$. secalis. a Plot disease score (area of visual symptoms measured on a 1-9 scale). b Total amount of $R$. secalis DNA (determined by qPCR analysis of selected leaves). c Relative disease expression (defined as the second principal component of a principal component analysis that were all in nearly identical positions to those identified using visual disease symptoms and they were flanked by the same markers. This appears to reflect the strength of the genetic correlation between the amount of pathogen DNA and severity of visual symptoms.

Resistance QTL identified using relative disease expression generally had much smaller probabilities associated with them than those associated with QTL for primary traits. Composite interval mapping identified three resistance QTL; two are located on $3 \mathrm{H}$ and $7 \mathrm{H}$ close to the QTL effects identified using the primary disease traits (flanked by the same markers as the primary traits). The final QTL was located on chromosome 5H between markers 11_21077 and 11_11497 (Table 2). of the two primary disease traits). Solid lines show how the probability (displayed on a $-\log _{10}$ scale) of an association between genotype and trait varies across each chromosome. Chromosomes are arranged sequentially along the $\mathrm{x}$-axis with the $0 \mathrm{cM}$ position for each chromosome at the left of each line. Dotted lines indicate the values of a test statistics equivalent to a genome-wide significance threshold of 0.05

Disease progression

An analysis of changes with time in visual plot disease scores across a single growing season (2008/ 2009) suggests that the heritability of plot scores remained generally consistent across all observations but that the additive genetic variance increased throughout the season (Table 3). Therefore, there was no evidence that the genetic basis of resistance varied during the course of a growing season.

\section{Discussion}

This work has identified two new QTL for resistance against $R$. secalis on barley chromosomes $2 \mathrm{H}$ and $7 \mathrm{H}$.

\begin{tabular}{|l|lll|}
\hline & Journal : Medium 10681 & Dispatch : 11-7-2011 & Pages : 10 \\
Article No. : 485 & $\square$ LE & $\square$ TYPESET \\
MS Code : EUPH4908 & $\bigcup_{\mathrm{CP}}$ & $\searrow$ DISK \\
\hline
\end{tabular}


Table 2 Summary of final QTL models for the three disease traits examined (a: Visual plot rhynchosporium score; b: Amount of $R$. secalis DNA; c: Relative disease expression), showing the chromosome, map position (and flanking markers) for each QTL identified. Also shown is the estimated additive QTL effect (in the same units as phenotypic scores) in each growing season for each of the QTL included in the final QTL model

\begin{tabular}{|c|c|c|c|c|c|}
\hline Locus & Chr & Position (cM) & Flanking markers & Effect 2007/2008 (SE) & Effect $2008 / 2009$ (SE) \\
\hline \multicolumn{6}{|c|}{ a: Visual plot score ${ }^{a}$} \\
\hline 1 & $2 \mathrm{H}$ & 179.1 & 11_10791-11_10085 & $-0.13(0.03)$ & $-0.13(0.03)$ \\
\hline 2 & $3 \mathrm{H}$ & 90.5 & 11_10515-11_20612 & $-0.24(0.03)$ & $-0.24(0.03)$ \\
\hline 3 & $7 \mathrm{H}$ & 110.9 & 11_11098-11_10169 & $-0.21(0.03)$ & $-0.21(0.03)$ \\
\hline \multicolumn{6}{|c|}{$b: R$. secalis $\mathrm{DNA}^{\mathrm{b}}$} \\
\hline 1 & $2 \mathrm{H}$ & 180.6 & 11_10791-11_10085 & $-305(528)$ & $-2,612(517)$ \\
\hline 2 & $3 \mathrm{H}$ & 99.6 & 11_10515-11_20612 & $-285(548)$ & $-4,008(538)$ \\
\hline 3 & $7 \mathrm{H}$ & 107 & 11_11098-11_10169 & $-120.3(650)$ & $-3,760(636)$ \\
\hline \multicolumn{6}{|c|}{ c: Relative disease expression ${ }^{\mathrm{c}}$} \\
\hline 1 & $3 \mathrm{H}$ & 86.6 & 11_10515-11_20612 & $0.18(0.04)$ & $0.18(0.04)$ \\
\hline 2 & $5 \mathrm{H}$ & 145 & 11_21077-11_11497 & $-0.16(0.04)$ & $-0.16(0.04)$ \\
\hline 3 & $7 \mathrm{H}$ & 111 & 11_11098-11_10169 & $0.35(0.06)$ & $0.35(0.06)$ \\
\hline
\end{tabular}

The standard error associated with the estimated QTL effect is shown in parentheses

${ }^{a}$ Plot disease score at GS50 measured on 1-9 scale (Newton and Hackett 1994) and normalized using a natural logarithmic transformation

b Amount of R. secalis DNA at GS50 measured in pg

c Relative disease expression at GS50, defined as the residuals from a SMA regression fitting the effect of the amount of $R$. secalis DNA on area of visual disease symptoms

Table 3 Estimates of heritability $\left(H^{2}\right)$ and additive genetic variance $\left(V_{\mathrm{a}}\right)$ of visual plot rhynchosporium scores at various measurement dates during the course of the 2008/2009 growing season

\begin{tabular}{lll}
\hline Measurement date & $H^{2}$ & $V_{\mathrm{a}}$ \\
\hline 22 April 2009 & 0.33 & 0.08 \\
01 May 2009 & 0.31 & 0.26 \\
14 May 2009 & 0.36 & 0.54 \\
19 May 2009 & 0.39 & 1.00 \\
09 June 2009 & 0.41 & 2.25 \\
23 June 2009 & 0.35 & 1.91 \\
\hline
\end{tabular}

These QTL effects are not associated with known be a useful resource for understanding and manipulating the interaction between host and pathogen.

The QTL effect identified on chromosome $3 \mathrm{H}$, which affected both area of disease symptoms and amount of $R$. secalis DNA, was associated closely with the known position of $s d w l$ (Barua et al. 1993). This effect is probably a pleiotropic effect of height that acts by limiting effective dispersal of pathogen spores by rain-splash during secondary spread of the disease (Fitt et al. 1988); indeed, this QTL co-locates with an extremely strong QTL effect for height detected in a separate (fungicide treated) field trial (data not shown). This reinforces the importance of disease escape as a component of field resistance to $R$. secalis. For all identified QTL, the winter parent supplied the resistant allele. This is consistent with the observation that winter barley types generally have a higher resistance rating than spring types. However, the absence of strong associations between positions of major vernalistation/flowering time loci and those of resistance QTL suggests that it is not growth habit per se that affects resistance, but rather that desirable resistance characters are associated with winter barley types. This would appear to validate the use of winter $x$

\begin{tabular}{|l|lll|}
\hline & Journal : Medium 10681 & Dispatch : 11-7-2011 & Pages : 10 \\
Article No. : 485 & $\square$ LE & $\square$ TYPESET \\
MS Code : EUPH4908 & $\checkmark$ CP & $\checkmark$ DISK \\
\hline
\end{tabular}


spring crosses to identify novel sources of resistance for incorporation into spring germplasm.

The similarity between the profiles of resistance QTL identified using visual disease symptoms and those identified using amount of $R$. secalis DNA appears to reflect the strength of the genetic correlation between these two traits. This result is unsurprising, given the nature of the relationship between them. Nevertheless, the low heritability of the resistance QTL identified using amount of $R$. secalis DNA suggests that the precision of the qPCR method may not compare favourably to that of conventional scoring of area of visual disease symptoms (this might be either due to insufficient sampling, or be inherent to the assay itself). In either case, it is possible that this is responsible for the relative weakness of the correlation between early growth stage qPCR scores and later visual symptom scores. Sampling a greater number of plants from within a plot, to produce a bulked sample would offer the possibility of improved precision without increasing costs associated with performing the qPCR assay. Whilst improving the precision of the $\mathrm{qPCR} /$ sampling protocol may help in making early season qPCR scores a useful predictor of later disease severity, other results have shown that variation in amounts of rainfall may be a major determinant of subsequent epidemic development (Fitt et al. 2010).

The results of the QTL genome scan using relative disease expression, whilst not conclusive, suggest that the degree to which any given amount of $R$. secalis colonisation causes symptom expression has a genetic basis in barley. Interestingly, for the best QTL effect for this trait (on chromosome $7 \mathrm{H}$ ), the spring parent (Cocktail) contributes the resistant allele, indicating that increased relative disease expression may be a pleiotropic effect of the resistant allele at this locus. Nevertheless, a weak QTL effect in the region of $3 \mathrm{H}$ containing $s d w 1$ (the effect of which is expected to be entirely due to disease escape) and the absence of identified QTL in regions not identified in the primary disease traits suggest that these effects are statistical artefacts. The other small QTL effect identified for this trait was on chromosome $5 \mathrm{H}$; this QTL does not correspond to those identified with the primary traits but in this case the winter barley parent contributes the resistant allele.

Clearly, the strength of the analysis of relative disease expression is only as good as that of the method used to derive the phenotypic data. Ideally, such phenotypes would be derived by directly measuring the symptomatic response of individual lines to varying amounts of pathogen colonisation. However, this approach requires a degree of control that is not practical to obtain in large-scale field experiments. The method used (SMA regression) here has been shown to be effective on simulated data sets but a more detailed statistical consideration of the problem of measuring relative disease expression in experimental data must be considered a priority.

The identification of apparently novel resistance loci confirms the value of winter barley germplasm as a source of resistance to $R$. secalis, and illustrates that mapping populations from crosses between winter and spring barley offer a method for identifying such resistance. The results show that the suppression of disease symptoms is a component of the expression of resistance mechanisms controlled by some genes but not others.

Acknowledgments The authors would like to thank the Scottish Government Rural and Environment Research and Analysis Directorate (RERAD), the Biotechnology and Biological Sciences Research Council (BBSRC) and the Sustainable Arable LINK programme for funding this research, and KWS for providing the mapping population used in the study. Thanks are also due to Professor John Lucas for his contributions to the project and to the estate staff at the James Hutton Institute, as well as Dr Christine Hackett for advice on statistical analysis. The authors also wish to thank two anonymous referees for useful comments and suggestions.

\section{References}

Abang MM, Baum M, Ceccarelli S, Grando S, Linde CC, Yahyaoui AH, Zhan J, McDonald BA (2006) Pathogen evolution in response to host resistance genes: evidence from fields experiments with Rhynchosporium secalis on barley. Phytopathology 96:S2

Atkins SD, Fitt BD, Fraaije BA, Harvey S, Lynott J, Newton AC (2010) The epidemiological importance of asymptomatic infection of winter barley by Rhynchosporium secalis and its consequences for crop protection and breeding. Proc Crop Prot Northern Britain 2010:81-86

Barua UM, Chalmers KJ, Thomas WTB, Hackett CA, Lea V, Jack P, Forster BP, Waugh R, Powell W (1993) Molecular mapping of genes determining height, time to heading, and growth habit in barley (Hordeum vulgare). Genome 36:1080-1087

Bearchell SJ, Fraaije BA, Shaw MW, Fitt BD (2005) Wheat archive links long-term fungal pathogen population dynamics to air pollution. Proc Natl Acad Sci USA 102:5438-5442

\begin{tabular}{|l|lll|}
\hline Journal : Medium 10681 & Dispatch : 11-7-2011 & Pages : 10 \\
Article No. : 485 & $\square$ LE & $\square$ TYPESET \\
MS Code : EUPH4908 & $\checkmark$ CP & $\checkmark$ DISK \\
\hline
\end{tabular}


Boer MP, Wright D, Feng LZ, Podlich DW, Luo L, Cooper M, van Eeuwijk FA (2007) A mixed-model quantitative trait loci (QTL) analysis for multiple-environment trial data using environmental covariables for QTL-by-environment interactions, with an example in maize. Genetics 177: 1801-1813

Brun H, Chevre AM, Fitt BDL, Powers S, Besnard AL, Ermel M, Huteau V, Marquer B, Eber F, Renard M, Andrivon D (2010) Quantitative resistance increases the durability of qualitative resistance to Leptosphaeria maculans in Brassica napus. New Phytol 185:285-299

Chen A, Baumann U, Fincher GB, Collins NC (2009) Flt-2L, a locus in barley controlling flowering time, spike density, and plant height. Funct Integr Genomics 9:243-254

Close T, Bhat P, Lonardi S, Wu Y, Rostoks N, Ramsay L, Druka A, Stein N, Svensson J, Wanamaker S, Bozdag S, Roose M, Moscou M, Chao S, Varshney R, Szucs P, Sato K, Hayes P, Matthews D, Kleinhofs A, Muehlbauer G, DeYoung J, Marshall D, Madishetty K, Fenton R, Condamine P, Graner A, Waugh R (2009) Development and implementation of high-throughput SNP genotyping in barley. BMC Genomics 10:582

Davis H, Fitt BDL (1990) Symptomless infection of Rhynchosporium secalis on leaves of winter barley. Mycol Res 94:557-560

Fitt BDL, Mccartney HA, Creighton NF, Lacey ME, Walklate PJ (1988) Dispersal of Rhynchosporium secalis conidia from infected barley leaves or straw by simulated rain. Ann Appl Biol 112:49-59

Fitt BD, Atkins SD, Fraaije BA, Lucas JA, Newton AC, Looseley ME, Werner P, Harrap D, Ashworth M, Southgate J, Phillips H, Gilchrist A (2010) Role of inoculum sources in Rhynchosporium population dynamics and epidemiology on barley. HGCA Final report, Project Number RD-2004-3099

Fountaine JA, Shaw MW, Napier B, Ward E, Fraaije BA (2007) Application of real-time and multiplex polymerase chain reaction assays to study leaf blotch epidemics in barley. Phytopathology 97:297-303

Fountaine JM, Shaw MW, Ward E, Fraaije BA (2010) The role of seeds and airborne inoculum in the initiation of leaf blotch (Rhynchosporium secalis) epidemics in winter barley. Plant Pathol 59:330-337

Hahn M, Jüngling S, Knogge W (1993) Cultivar-specific elicitation of barley defense reactions by the phytotoxic peptide NIP1 from Rhynchosporium secalis. Mol Plant Microbe Interact 6:745-754

Hanemann A, Schweizer GF, Cossu R, Wicker T, Roder MS (2009) Fine mapping, physical mapping and development of diagnostic markers for the Rrs 2 scald resistance gene in barley. Theor Appl Genet 119:1507-1522
Lehnackers H, Knogge W (1990) Cytological studies on the infection of barley cultivars with known resistance genotypes by Rhynchosporium secalis. Can J Bot-Rev Can Bot 68:1953-1961

Li J, Ji L (2005) Adjusting multiple testing in multilocus analyses using the eigenvalues of a correlation matrix. Heredity 95:221-227

Newton AC, Hackett CA (1994) Subjective components of mildew assessment on spring barley. Eur J Plant Pathol 100:395-412

Newton AC, Searle J, Guy DC, Hackett CA, Cooke DEL (2001) Variability in pathotype, aggressiveness, RAPD profile, and rDNA ITS1 sequences of UK isolates of Rhynchosporium secalis. Z Pflanzenk Pflanzen 108:446-458

Newton AC, Swanston JS, Guy DC (2004) Enhanced durability and utility of genes for resistance by deployment in cultivar mixtures. In: Proceedings of molecular plant-microbe interactions XI, St Petersburg, 18-26 July 2003, pp 240-243

Payne RW, Murray DA, Harding SA, Soutar DM (2009) GenStat for Windows (12th edn) introduction. VSN International, Hemel Hempstead

Thomas WTB, Newton AC, Wilson A, Meyer RC, Young GR, Lawrence PE (2010) QTLs for disease resistance mapped in Derkado x B83-12/21/5. Barley genetics VIII In: Proceedings of the 8th International Barley Genetics Symposium, Adelaide, pp 186-188

Turkington T, Burnett PA, Briggs KG, Xi K (1998) Screening for scald resistance for future Alberta barley varieties Final report, Alberta Barley Commission Project No. 60-058

Van Ooijen JW (2006) JoinMap ${ }^{\circledR} 4$ Software for the calculation of genetic linkage maps in experimental populations of diploid species. Kyazma BV, Wageningen, The Netherlands

Walters DR, McRoberts N, Fitt BDL (2008) Are green islands red herrings? Significance of green islands in plant interactions with pathogens and pests. Biol Rev 83:79-102

Xi K, Xue AG, Burnett PA, Helm JH, Turkington TK (2000) Quantitative resistance of barley cultivars to Rhynchosporium secalis. Can J Plant Pathol-Rev Can Phytopathol 22:217-223

Zadoks JC, Chang TT, Konzak CF (1974) A decimal code for the growth stages of cereals. Weed Res 14:415-421

Zhan J, Fitt BDL, Pinnschmidt HO, Oxley SJP, Newton AC (2008) Resistance, epidemiology and sustainable management of Rhynchosporium secalis populations on barley. Plant Pathol 57:1-14

\begin{tabular}{|l|ll|} 
Journal : Medium 10681 & Dispatch : 11-7-2011 & Pages : 10 \\
Article No. : 485 & $\square$ LE & $\square$ TYPESET \\
MS Code : EUPH4908 & $\checkmark \mathrm{CP}$ & $\checkmark$ DISK \\
\hline
\end{tabular}

